\title{
Trends in Male Contraceptive Use in Ghana: An Analysis of Self-Reported Contraceptive Use from GDHS 2003, 2008 and 2014
}

\author{
Cyril Alando \\ University of Ghana School of Public Health \\ Adom Manu ( $\nabla$ abumanu@yahoo.com ) \\ University of Ghana School of Public Health \\ Helen Habib \\ University of Ghana School of Public Health \\ Emefa Modey \\ University of Ghana School of Public Health \\ Kwasi Torpey \\ University of Ghana School of Public Health \\ Richard Adanu \\ University of Ghana School of Public Health \\ Augustine Ankomah \\ Population Council Ghana
}

Research

Keywords: Trend Analysis, Male Contraception, Family Planning, Ghana

Posted Date: September 18th, 2020

DOI: https://doi.org/10.21203/rs.2.19849/v2

License: (ㅇ) (1) This work is licensed under a Creative Commons Attribution 4.0 International License. Read Full License 


\section{Abstract}

Background: Male participation in contraception is proven to have positive outcomes on reproductive health and remains a critical issue of public health importance. However, there is a dearth of evidence on men's share of the contraceptive burden among couples in Ghana. Knowledge of the trends and trajectories of men's contraceptive practice could inform male focused programmatic interventions to boost contraceptive use for effective fertility regulation. This study examined the trends in contraceptive use as reported by men.

Methods: This paper examines trends in self-reported contraceptive use among sexually active Ghanaian males, using data from the three most recent national Demographic and Health Surveys (2003, 2008 and 2014). Frequency distributions of socio-demographic and background characteristics were used to describe the sample by each survey year. The $Z$ test of proportions was used to identify significant differences in the estimated proportions and subgroups of men using contraceptives by survey year. The Combined data from the three nationally representative surveys were analyzed, accruing a sample of 9,008, comprising (GDHS 2003=3,104; GDHS 2008=3,007; and GDHS 2014=2,897) male respondents who met the inclusion criteria.

Results: Men's contraceptive use appears to have declined over the last three demographic surveys despite an increase in the proportion of sexually active males. However, a significant proportion of men who used contraception (44.5\% - 41.5\%) still relied on the male condom as their primary choice of contraception. Place of residence, educational attainment, occupation, region of residence and religious affiliation were all found to be significantly associated with contraceptive use consistency.

Conclusion: There has been a significant decrease in contraceptive use by Ghanaian men between 2003 and 2014 . Although the male condom appears to be the most popular modern male contraceptive method, especially during adolescence, along the life course the phenomenon changes, with a shift towards modern female methods. There is therefore, the need for family planning service providers, policymakers and all relevant stakeholders to consciously target men with contraceptive products and services and community engagement to improve FP uptake

\section{Background}

Contraceptive use is a phenomenon of public health importance in Ghana, like it is in many developing countries [1]. In this paper, male contraceptive use is defined as the use of any method, medicine or device, targeting sperm production or function, by a male and/or his partner to prevent pregnancy [2-4]. And this remains an issue of public health significance because of the potential reproductive health and demographic benefits $[2,5]$.

One of the highlights of the 1994 International Conference on Population and Development (ICPD) was male involvement in family planning, and effort to achieve this has grown since then [6,7]. However, the use of male contraceptives (MC) as part of men's active involvement in FP, and as a share of the overall contraception burden. An examination of the use of male contraceptives worldwide revealed that contraceptive methods that are directly used by men, or those that require men's co-operation to use account for about $25 \%$ of all contraceptive use worldwide [8].

That notwithstanding, there are varying degrees of $\mathrm{MC}$ use and its associated factors that have been reported by various studies [9-11].

Over the past half century in Ghana, contraception and family planning (FP) practices have been regarded as central in addressing issues of reproductive health as well as social and developmental challenges related to high population growth in Ghana. The country promulgated its initial National Population Policy in 1969, revised it in 1994 and implemented several policies including contraceptive social marketing; target setting to improve contraceptive prevalence rate (CPR) and reduce the total fertility rate (TFR); and in effect decrease growth rate by 2020 . However, these targets were not met during the implementation, and that led to the development of a roadmap for a comprehensive strategy to restructure FP practices in Ghana in 2005 [12]. Currently, Ghana has the Ghana Family Planning Costed Implementation Plan (GFCIP), following similar programs like the 20062010 policy dubbed A Road Map for Repositioning Family Planning in Ghana and the 2010-2013 Ghana Shared Growth and Development Agenda, which aimed to increase contraceptive use through various interventions; including active male partner involvement in contraception. Yet male contraceptive use continues to remain quite low.

The 2014 Ghana Evidence from nationally representative surveys in Ghana, such as the Demographic and Health Survey (DHS) and the Ghana Maternal Health Surveys (GMHS) report sharp contraceptive method use differentials between men and women. The 2017 GMHS revealed a consistently low (1.1\%) male condom use among the four most popular contraceptive methods (injectable, implants, the pill and male condom) used by currently married women [13].

Historically, women have been the main target of FP and contraception with less emphasis on male contraceptive use [14,15]. Although in many familial settings in Africa, men are and continue to be dominant decision-makers on fertility and contraception $[9,16]$, programs on family planning continue to focus less on them, making men view contraception mainly as that of a woman's responsibility [11,17]. This disproportionately focus of FP or contraception on only women $[18,19]$ and female adolescents $[20,21]$ includes research and publications, explaining why there is a dearth of evidence on male contraceptive use.

Given that effective fertility regulation requires active male participation, including their use of contraceptives, it is necessary to track the trends in men's contraceptive use over time to aid planning and design of policies and programs that promote family planning and fertility regulation [22-25]. This 
study therefore, assesses the trends in men's use of contraception in Ghana from 2003 - 2014.

\section{Methods}

\section{Study design}

This study analyzed secondary data from the three most recent Demographic and Health Surveys of 2003, 2008, 2014 conducted in Ghana. These are nationally representative, cross-sectional, analytical studies usually conducted in five (5)-year intervals. The surveys are carried out in association with the Ghana Statistical Service (GSS) and Ghana Health Service (GHS).

\section{Sample design and sampling}

The country's general population as projected by the Population and Housing Censuses (PHCs) serves as the sampling frames for the Ghana Demographic and Health Survey (GDHS) data collection with the exclusion of institutional (hotels, barracks, and prisons) and nomadic populations. The GDHS employs a two-stage sampling design; the first stage selects sample points or clusters consisting of enumeration areas (EAs) as demarcated by the GSS for the PHCs. The second stage involved systematic sampling of approximately 30 households per selected EA. Weighting factors were applied to the data to ensure nationally representative results.

\section{Questionnaires}

The GDHS uses three standard DHS questionnaires: Household, Woman's, and Man's Questionnaires tailored to mirror population and health issues in Ghana. Based on this paper's interest, the authors used data from the Man's Questionnaires of the three GDHS datasets, involving men aged 15-59 years.

\section{Sample}

The inclusion criterion was all male respondents aged 15-59 years at the time of each GDHS. Men who had not been sexually active in the past six months, or who needed a child within one (1) year of the survey were excluded. Men with an infecund or currently pregnant partner were also excluded. Out of the total sample of 13,971 (GDHS 2003, n=5,015; GDHS 2008, n=4,568; and GDHS 2014, n=4,388) respondents for the three (3) surveys, a qualified sample of 9,008 (GDHS 2003, n=3,104; GDHS 2008, n=3,007; and GDHS 2014, n=2,897) respondents were extracted for the analysis.

\section{Data extraction}

Data was downloaded from the MEASURE DHS website after access was sought and granted. The recode manuals and the man's questionnaires for the three surveys were reviewed to identify appropriate variables of interest. Variables identified were coded and labelled to ensure inter-survey uniformity and standardization in variable code

\section{Variables}

The variables that were used for this analysis were informed by relevant literature which detailed various determinants of contraceptive use among men. The outcome of interest, male contraception (men's contraceptive use), was defined as the use of contraception by male respondent or partner during last sexual intercourse at the time of each survey. On the other hand, the predictor variables for the analysis were the socio-demographic, and sexual and reproductive health characteristic of respondents.

\section{Data analysis}

The data were analyzed using STATA version 15. Descriptive statistics showing frequency distributions and proportions of respondents by sociodemographic and other background factors were carried out, summarized and presented in tables, graphs and charts. Bivariate analysis using the Ztest of proportions was used to identify significant differences in identified proportions. Logistic regression was used to identify significant predictors of men's contraceptive use for each GDHS survey year. Based on the outcomes, contingency tables were generated, and results were reported at $95 \%$ confidence interval.

\section{Results}

\section{Socio-demographic characteristics}

Table 1 presents socio-demographic characteristics of respondents. In all the three surveys, a higher proportion of males were aged 25-39 years. The mean age of participants between 2003 and 2014 did not change: 35 \pm 11.1 in 2003 and 35 \pm 11.6 in 2014 . There was a decline in the proportion of men who had never been to school - from $17.6 \%$ in 2003 to $10.8 \%$ in 2014 The proportion of rural dwellers dipped from $54.0 \%$ to $52.8 \%$ to $46.9 \%$, characterizing growing urbanisation. The proportion of men living below the middle class (poorest and poorer quintiles) decreased from $34.0 \%$ in 2003 to $32.2 \%$ in 2014 . 
Table 2 presents demographic and sexual and reproductive health characteristics of participants. The proportion of married men reduced by approximately 8 percentage points, while the proportion of men who had never married or been in a recognised union increased by about 7 percentage points. Men's knowledge of any contraceptive method appeared almost universal over the period (99.6\% - 99.7\%) although a small proportion (4.4\% $5.6 \%$ reported uneasy access to contraceptives like condoms.

\section{$<<$ Insert Table 1 >}

\section{$\ll$ Insert Table 2 »}

\section{Trends in contraceptive use among men: 2003 - 2014}

A downward trend in contraceptive use among sexually active Ghanaian men was noted from analysis. Contraceptive use declined from $44.3 \%$ in 2003 to $35.6 \%$ in 2014 , suggesting a nearly one (1) percentage point decline per annum over the ten-year interval. Conversely, there was an increasing trend in sexual activity among Ghanaian males over the same period of time from $77 \%$ to $81.3 \%$, widening the gap between sexual activity and contraceptive use (Figure1).

Changes observed in male contraceptive use were significant overall $(z=6.84, p<0.001)$ between 2003 and 2014. However, the inter-survey difference was only significant between 2003 and $2008(z=6.75, p<0.001)$ as shown in Table 3.

\section{$\ll$ Insert Table 3 »>}

Pattern of men's contraceptive method preference at last sex among users: 2003 - 2014.

The analysis revealed that among the proportion of men who reported contraceptive use at last sexual intercourse, there was a drop from 2003(44.5\%) to $2014(41.5 \%)$ in male condom use across the period of the study. Modern female methods (the pill, IUD, injectable, implant, female condom, female sterilization) increased by more than 10 percentage points $(28.8 \%-39.4 \%)$, with male sterilization being the least preferred method (0.1\%). However, a continuous decline occurred from 2003(26.6\%) to 2014(19.0\%), in Traditional/other methods such as withdrawal, rhythm. (See Figure 2).

\section{Trends in male contraceptive use by selected socio-demographics (2003 - 2014).}

Among men who reported contraceptive use at last sexual intercourse, the majority ( $81.6 \%$ in 2003 to $83.0 \%$ in 2014 ) of adolescents used modern male methods, namely male condom and vasectomy/male sterilization. However, an increasing shift in contraceptive method from male condom to modern female methods was observed among men aged 40 years and above from 2003 (45.1\%) to 2014 (62.3\%). These differences were statistically significant across all surveys ( $p<0.001$ ). An increasing proportion of contraceptive users from $2003(34.3 \%)$ to 2014 (63.6\%) who relied on modern female methods had no formal education.

Difference in inter-regional method preference by users was significant for each survey $(\mathrm{p}<0.001)$. By religion, modern methods use increased for both male (43.6\% - 52.5\%) and female methods (23.3\% -29.5\%) among catholic men, with a 13.2 percentage point drop in traditional/other method use (31.2\% - 18.0\%) between 2003 and 2014. This difference in religious distribution of contraceptive use was significant for 2003 ( $p<0.001)$ and 2014 $(p<0.01)$ as shown in Table 4.

\section{$\ll<$ Insert Table 4 >}

The results (Table 5) shows that over a third of male adolescents (35.3\%-34.5\%) [2003 - 2008] had never used any contraception, and over the same period, an increasing proportion (23.1\%-30.6\%) reported inconsistent contraceptive use. Conversely, majority of men aged 40 years and above were inconsistent contraceptive users in 2003(35.4\%) and 2008(44.6\%). This difference in contraceptive use consistency between age groups was statistically significant $(p<0.001)$ in the two surveys.

Between 2003 and 2008, over a third of rural dwelling men had never used contraceptives (33.9\%-33.7\%), whilst consistent rural male contraceptive users decreased from $36.4 \%$ to $28.4 \%$. The majority of men with no formal education had never used contraceptives (58.0\%-61.5\%) compared to their counterparts with tertiary education $(8.6 \%-8.8 \%)$.. Place of residence, Educational attainment, occupation, region of residence and religious affiliation were all statistically significant with men's contraceptive use consistency in the two surveys $(p<0.001)$.

\section{$\ll$ Insert Table 5 >}

\section{Discussion}

\section{Trend in contraceptive use among males in Ghana from 2003-2014}

This paper found a significant decline in overall contraceptive use as reported by men. The inter-survey test of proportions showed that the difference was significant between 2003 and 2008. Similar trends had been observed in Nigeria [23] where an initial increase from 2003 - 2005 and a later decrease from 2005 - 2007 occurred. The recorded high proportions of sexually active and inexperienced adolescents, married men who desire more 
children, or view contraceptive use as solely that of a woman's responsibility, may have accounted for the contraceptive non-use along the reproductive years as observed in this paper.

Geographically, men from rural Ghana and those without formal education are less likely to use modern male contraceptives than their urban and educated counterparts. The results of this study, mirrors findings in a Nigerian study which also identified differences in contraceptive use by geographical location [23], and [26,27] who separately reported that educational attainment was significantly associated with contraceptive choices. This may be because many rural dwellers have no formal education and consequently have poor knowledge about contraception variants. Additionally, rural socio-cultural norms that promote fertility and mitigate contraceptive uptake, as well as issues of access may be accountable for these differences.

This suggests a need for locally-adapted interventions for men with no formal education who work in informal sectors, such as the use of behavior change communication in local languages and with community engagement.

Geographically, more than half of men in 2003 and 2008 from the Savanna-North had never used contraceptives than men from the other regions of the country. These findings are consistent with other studies in Ghana which reported significant socio-demographic variations in contraceptive use $[26,28-31]$. The findings in this study may be due to the men in the Savanna-North region having more Islamic, Traditional and other religions as well as be rural dwellers, all of which are known to influence fertility and contraceptive decisions [32,33].

The Ghanaian male adolescent population is steadily increasing, and a greater proportion of males initiated sexual intercourse during adolescence in 2014 than did in 2003. This may be attributable to the fact that adolescents probably becoming more exposed to growing urbanisation and peer pressure from school and other social groupings. This study however discovered that between 2003 and 2008, more than a third of adolescents had never used contraception, whilst a smaller proportion were inconsistent contraceptive users. This suggests a need for special attention towards male adolescent sexual reproductive health needs particularly, on contraceptive use.

The analyses also discovered a decline in ease of contraceptive access as reported by respondents. The proportion of men who said it was easy to access condoms if they needed one dropped from 2003 to 2014. This phenomenon may be attributable to an increasing male adolescent population, who without specialised service centres to address their needs will report difficulties in accessing contraceptives, including condoms.

\section{Pattem of men's contraceptive method preference at last sex among users: 2003-2014}

Results for the period between 2003 and 2014 show that among contraceptive users, there was an overall increase in the reliance on modern female methods (the pill, IUD, injectable, implant, female condom, female sterilization), although a significant proportion of users still relied on the male condom at last sex. This correlated with findings by [34] in the Volta region of Ghana, which reported condom as the most ( $90 \%$ ) accessed method. [35]also reported that almost a third of secondary school male students consistently used the condom. These findings are in contrast to other studies that report the underutilization of male condoms $[10,36]$. This increasing reliance may be attributable to the male condom being the only available, wellknown, easily accessible and reversible modern male-dependent method. Literature establishes that men will be more likely to use a method they know about; which they consider safe and effective; available; and grants autonomy of use [37-39].

\section{Study limitations}

Like any other survey, the data used in this study was subject to recall bias and evasion or misreporting on sensitive issues. These issues are particularly encountered when surveys retrospectively collect data spanning a period of five (5) years preceding it. Also, it may be difficult for men to know and report their partners' actual contraception status. This analysis, however, utilizes the most reliable nationally representative data, believed to have captured the true reports, of sexually active Ghanaian men who are effectively involved in contraceptive decision-making with their partners.

\section{Conclusions And Recommendations}

\section{Conclusions}

This paper makes an important contribution to literature by demonstrating the need for men to be factored into sexual and reproductive health issues and for proposing improvements required for effective contraception inclusiveness as an intervention for improving male involvement in FP and overall sexual and reproductive health for men and their partners. The study reveals that there has been a significant decrease in contraceptive use by men from 2003 to 2014. The male condom was the most common modern contraceptive method men use, especially during adolescence; and along the life course it shifts towards modern female methods such as the pill, IUD, injectable, implant, female condom, female sterilization. Whereas the proportion of male adolescents is increasing, more than a third of it has never used contraception of any sort. Finally, significant geographical and educational differences in contraceptive utilization exist among Ghanaian men.

\section{Recommendations}

From the findings made in this paper, the following policy interventions were recommended: 
- Government in collaboration with FP Service providers and program implementers should continuously focus programs and policies towards improving men's contraceptive use;

- FP interventions such as regular male-focused outreach FP services including counselling, and male-directed advocacy drives within catchment areas, should be implemented to get men informed, and, to understand the benefits of limited family sizes to the family and country.

- FP Service providers and policymakers should consciously engage local authorities, men, traditional and religious groups and other relevant stakeholders in all-inclusive approaches such as community engagement to improve FP uptake.

- Interventions should be tailored and specific to the needs of sub-population groups including the use of variable behavior change communications to ensure improved satisfaction and acceptability.

\section{Abbreviations}

$\begin{array}{llll}\text { CPR } & - & \text { Contraceptive prevalence rate } \\ \text { DHS } & - & \text { Demographic and Health Survey } \\ \text { EAs } & - & \text { Enumeration Areas } \\ \text { FP } & - & \text { Family Planning } \\ \text { GDHS } & - & \text { Ghana Demographic and Health Survey } \\ \text { GFCIP } & - & \text { Ghana Family Planning Costed Implementation Plan 2016-2020 } \\ \text { GHS } & - & \text { Ghana Health Services } \\ \text { GSS } & - & \text { Ghana Statistical Service } \\ \text { ICPD } & - & \text { International Conference on Population and Development } \\ \text { MC } & - & \text { Male Contraceptive(s) } \\ \text { GMHS } & - & \text { Ghana Maternal Health Survey } \\ \text { PHC } & - & \text { Population and Housing Census } \\ \text { TFR } & - & \text { Total Fertility Rate } \\ \text { UGSPH } & - & \text { University of Ghana School of Public Health } \\ \text { WHO } & - & \text { World Health Organization }\end{array}$

\section{Declarations}

\section{Ethical approval and consent to participate}

The first author submitted a request to and obtained a permission from Measure DHS to use the data for this study. The DHS sought Ethical approval for the data collection from the Ethical Review Committee of Ghana Health Service, Accra, Ghana, and the Institutional Review Board of ICF International, USA, for all three surveys. Each respondent provided informed verbal and/or written consent to participate in the study. The authors affirm that all procedures contributing to this work comply with the ethical standards of the relevant national and institutional committees on human subjects.

\section{Consent for publication}

Not applicable.

\section{Availability of data and materials}

The datasets analysed for this study are available to the public freely at MEASURE DHS, www.measuredhs.com. The MEASURE DHS standard questionnaires for the three surveys were used and can be found at http://dhsprogram.com/publications/publications-FR307-DHS-Final-Reports.cfm.

\section{Competing interests}

The authors declare no competing interests.

\section{Funding}


CA received funding from the HRP Alliance, part of the UNDP-UNFPA-UNICEF-WHO-World Bank Special Program of Research, Development and Research Training in Human Reproduction (HRP), a cosponsored program executed by the World Health Organization (WHO), to complete his studies. This article represents the views of the named authors only and does not represent the views of the World Health Organization.

\section{Authors' contributions}

CA conceived the study and AM, EM and AA contributed to its design. CA, AM, EM, HH AA and KT, made substantial contributions to data analysis plan, and CA performed all statistical analyses. All authors contributed to interpretation of data. CA drafted the initial version of the manuscript, it was revised thoroughly by $\mathrm{HH}, \mathrm{AM}, \mathrm{EM}$ and $\mathrm{AA}$. $\mathrm{AM}, \mathrm{HH}, \mathrm{EM}, \mathrm{KT}, \mathrm{RA}$ and $\mathrm{AA}$ critically reviewed subsequent versions of the manuscript for intellectual content. All authors read and approved the final manuscript.

\section{Acknowledgements}

The authors acknowledge the Measure DHS for granting access and permission to use their datasets for this study. The support of the WHO/HRP Alliance and its Regional hub at the University of Ghana School of Public Health is acknowledged. Finally, the authors would also like to thank Mr. Emmanuel Aidoo for his STATA programming assistance.

\section{References}

1. Weber RFA, Dohle GR. Male contraception: Mechanical, hormonal and non-hormonal methods. World J Urol. 2003;21(5):338-40.

2. Amory JK, Page ST, Bremner WJ. Drug insight: recent advances in male hormonal contraception. Nat Clin Pract Endocrinol Metab. 2006; doi:10.1038/ncpendmet0069.

3. Marcell A V., Pilgrim N, Jennings JM, Sanders R, Page KR, Loosier PS, et al. Young men's overall perceived quality of care: role of sexual and reproductive health and patient-centered care. J Adolesc Heal. 2017; doi:10.1016/j.jadohealth.2016.10.090.

4. Office on Women's Health [OWH]. A fact sheet from the office on women's health. Birth Control Methods. 2011. https://www.womenshealth.gov/files/fact-sheet-birth-control-methods.pdf. Accessed 1 Oct 2017.

5. Aaltonen P, Amory JK, Anderson RA, Behre HM, Bialy G, Blithe D, et al. 10th Summit Meeting Consensus: Recommendations for Regulatory Approval for Hormonal Male Contraception. J Androl. 2006; doi:10.2164/jandrol.106.002311.

6. Hardee K, Croce-Galis M, Gay J. Are men well served by family planning programs? Reprod Health. 2017; doi:10.1186/s12978-017-0278-5.

7. Ringheim K. Reversing the downward trend in men's share of contraceptive use. Reprod Health Matters. 1999;7(14):83-96.

8. Ross J, Hardee K. Use of male methods of contraception worldwide. Journal of Biosocial Science. 2016; doi:10.1017/S0021932016000560.

9. Adewuyi A, Ogunjuyigbe P. The Role of Men in Family Planning: An Examination of Men's Knowledge and Attitude to Contraceptive Use among the Yorubas. African Popul Stud. 2003; doi:10.3389/fpubh.2014.00137.

10. Addis ME, Mahalik JR. Men, masculinity, and the contexts of help seeking. Am Psychol. 2003; doi:10.1037/0003-066X.58.1.5.

11. Miller G, Valente C. Population Policy: Abortion and Modern Contraception Are Substitutes. Demography. 2016; doi:10.1007/s13524-016-0492-8.

12. GHS, UNFPA. Implications of the 2014 DHS Findings for Family Planning Programming in Ghana: Day of Dialogue on Family Planning in Ghana. Accra, Ghana; 2015.

13. Ghana Statistical Service [GSS], Ghana Health Service [GHS], ICF. Ghana Maternal Health Survey 2017. Key Indicators Report. Accra, Ghana; 2018.

14. Egbe TO, Ketchen SA, Eta-Nkongho E, Ekane GEH, Belley-Priso E. Risk Factors and Barriers to Male Involvement in the Choice of Family Planning Methods in the Buea Health District, South West Region, Cameroon: A Cross-Sectional Study in a Semi-Urban Area. Women Heal Open J. 2016; doi:10.17140/WHOJ-1-112.

15. Adongo PB, Tapsoba P, Phillips JF, Tabong PT-N, Stone A, Kuffour E, et al. The role of community-based health planning and services strategy in involving males in the provision of family planning services: a qualitative study in Southern Ghana. Reprod Health. 2013; doi:10.1186/1742-475510-36.

16. Kassa M, Abajobir AA, Gedefaw M. Level of male involvement and associated factors in family planning services utilization among married men in Debremarkos town, Northwest Ethiopia. BMC Int Health Hum Rights. 2014; doi:10.1186/s12914-014-0033-8.

17. Akafuah RA, Ossou M-A. Attitudes toward and Use of Knowledge about Family Planning among Ghanaian Men. Int J Men's Heal. 2008; doi:10.3149/jmh.0702.109. 
18. Beson P, Appiah R, Adomah-Afari A. Modern contraceptive use among reproductive-aged women in Ghana: prevalence, predictors, and policy implications. BMC Womens Health. 2018; doi:10.1186/s12905-018-0649-2.

19. Aviisah PA, Dery S, Atsu BK, Yawson A, Alotaibi RM, Rezk HR, et al. Modern contraceptive use among women of reproductive age in Ghana: analysis of the 2003 - 2014 Ghana Demographic and Health Surveys. BMC Womens Health. 2018; doi:10.1186/s12905-018-0634-9.

20. Agyemang J, Newton S, Nkrumah I, Tsoka-Gwegweni JM, Cumber SN. Contraceptive use and associated factors among sexually active female adolescents in Atwima Kwanwoma District, Ashanti region-Ghana. Pan Afr Med J. 2019; doi:10.11604/pamj.2019.32.182.15344.

21. Nyarko SH. Prevalence and correlates of contraceptive use among female adolescents in Ghana. BMC Womens Health. 2015; doi:10.1186/s12905015-0221-2.

22. Darroch JE, Singh S. Trends in contraceptive need and use in developing countries in 2003,2008 , and 2012: An analysis of national surveys. The Lancet. 2013; doi:10.1016/S0140-6736(13)60597-8.

23. Adebayo SB, Gayawan E, Ujuju C, Ankomah A. Modelling geographical variations and determinants of use of modern family planning methods among women of reproductive age in nigeria. J Biosoc Sci. 2013; doi:10.1017/S0021932012000326.

24. Tarico V. Better Birth Control for Men: 8 Promising Possibilities. 2013. https://rewire.news/article/2013/10/02/better-birth-control-for-men-8promising-possibilities/. Accessed 1 Oct 2017.

25. Packer C, Petruney T. Meet the Demand for Modern Contraception and Reproductive Health. Campaign Brief. 2016. http://womendeliver.org/wpcontent/uploads/2016/04/Good_Campaign_Brief_2_092016.pdf. Accessed 29 Sep 2017.

26. Balogun O, Adeniran A, Fawole A, Adesina K, Aboyeji A, Adeniran P. Effect of male partner's support on spousal modern contraception in a low resource setting. Ethiop J Health Sci. 2016; doi:10.4314/ejhs.v26i5.5.

27. Achana FS, Bawah AA, Jackson EF, Welaga P, Awine T, Asuo-Mante E, et al. Spatial and socio-demographic determinants of contraceptive use in the Upper East region of Ghana. Reprod Health. 2015; doi:10.1186/s12978-015-0017-8.

28. Hill NJ, Siwatu M, Robinson AK. "My Religion Picked My Birth Control": The Influence of Religion on Contraceptive Use. J Relig Health. 2014; doi:10.1007/s10943-013-9678-1.

29. Kramer MR, Rowland Hogue CJ, Gaydos LMD. Noncontracepting Behavior in Women at Risk for Unintended Pregnancy: What's Religion Got to Do With It? Ann Epidemiol. 2007; doi:10.1016/j.annepidem.2006.10.016.

30. Decat P, De Meyer S, Jaruseviciene L, Orozco M, Ibarra M, Segura Z, et al. Sexual onset and contraceptive use among adolescents from poor neighbourhoods in Managua, Nicaragua. Eur J Contracept Reprod Heal Care. 2015; doi:10.3109/13625187.2014.955846.

31. Curtis S, Evens E, Sambisa W. Contraceptive discontinuation and unintended pregnancy: an imperfect relationship. Int Perspect Sex Reprod Health. 2011; doi:10.1363/3705811.

32. Tabong PT-N, Adongo PB. Understanding the Social Meaning of Infertility and Childbearing: A Qualitative Study of the Perception of Childbearing and Childlessness in Northern Ghana. PLoS One. 2013; doi:10.1371/journal.pone.0054429.

33. Adongo PB, Phillips JF, Binka FN. The influence of traditional religion on fertility regulation among the Kassena-Nankana of northern Ghana. Stud Fam Plann. 1998; doi:10.2307/172179.

34. Wilson HW, Ameme D, llesanmi OS. Contraceptive Methods Accessed in Volta Region, Ghana, 2009 - 2014. Int Sch Res Not. 2017; doi: $10.1155 / 2017 / 7257042$.

35. Tarkang EE. Factors influencing consistent condom use among secondary school male students in Limbe Urban City, Cameroon. J Sci Res Reports. 2015; doi:10.9734/JSRR/2015/11334.

36. Kogan P, Wald M. Male contraception: History and development. Urol Clin North Am. 2014; doi:10.1016/j.ucl.2013.08.012.

37. Adongo PB, Tapsoba P, Phillips JF, Tabong PT-N, Stone A, Kuffour E, et al. "If you do vasectomy and come back here weak, I will divorce you": a qualitative study of community perceptions about vasectomy in Southern Ghana. BMC Int Health Hum Rights. 2014; doi:10.1186/1472-698X-1416.

38. Lopez LM, Steiner M, Grimes DA, Hilgenberg D, Schulz KF. Strategies for communicating contraceptive effectiveness. Cochrane Database Syst Rev. 2013; doi: 10.1002/14651858.CD006964.pub3.

39. van Wersch A, Eberhardt J, Stringer F. Attitudes towards the male contraceptive pill: psychosocial and cultural explanations for delaying a marketable product. Basic Clin Androl. 2012; doi: 10.1007/s12610-012-0185-4. 
Tables

Table 1: Socio-demographic characteristics of respondents

\begin{tabular}{|c|c|c|c|}
\hline \multirow[t]{2}{*}{ Socio-demographic characteristic } & 2003 & 2008 & 2014 \\
\hline & $\mathrm{n}(\%)$ & $\mathrm{n}(\%)$ & $\mathrm{n}(\%)$ \\
\hline \multicolumn{4}{|l|}{ Age groups } \\
\hline $15-19$ & $197(6.9)$ & $198(6.5)$ & $205(7.6)$ \\
\hline $20-24$ & $453(14.2)$ & $479(16.0)$ & $444(14.6)$ \\
\hline $25-39$ & 1496(48.3) & $1369(46.2)$ & $1277(44.1)$ \\
\hline $40+$ & $958(30.5)$ & $961(31.3)$ & $971(33.7)$ \\
\hline \multicolumn{4}{|l|}{ Educational Attainment } \\
\hline No education & $695(17.6)$ & $571(15.3)$ & $451(10.8)$ \\
\hline Some/completed primary & $434(13.6)$ & $414(12.8)$ & $408(12.5)$ \\
\hline Some secondary & $1428(50.0)$ & $1276(45.2)$ & $1289(48.3)$ \\
\hline Completed Secondary & $305(10.7)$ & $441(15.8)$ & $410(14.7)$ \\
\hline Tertiary & $242(8.2)$ & $305(11.0)$ & $339(13.7)$ \\
\hline \multicolumn{4}{|l|}{ Ethno-cultural Groups } \\
\hline Akan & $1325(49.3)$ & $1252(48.6)$ & $1218(50.3)$ \\
\hline $\mathrm{Ga} /$ Dangme & $215(7.6)$ & $190(6.9)$ & $207(9.6)$ \\
\hline Ewe & $403(13.5)$ & $429(14.4)$ & $362(13.9)$ \\
\hline Guan & $123(3.7)$ & $77(2.5)$ & $81(2.2)$ \\
\hline Northern Tribes & $871(20.6)$ & $916(22.7)$ & $966(21.4)$ \\
\hline Others & $164(5.3)$ & $140(4.8)$ & $63(2.5)$ \\
\hline \multicolumn{4}{|l|}{ Religion } \\
\hline No Religion & $243(7.5)$ & $173(5.5)$ & $192(6.8)$ \\
\hline Roman Catholic & $485(14.5)$ & $470(14.2)$ & $428(11.2)$ \\
\hline Other Christians & $1582(56.1)$ & $1579(58.5)$ & $1540(62.2)$ \\
\hline Islam & $606(17.5)$ & $539(15.9)$ & $570(16.4)$ \\
\hline Trad./Others & $187(4.3)$ & $245(5.9)$ & $167(3.4)$ \\
\hline \multicolumn{4}{|l|}{ Region (of residence) } \\
\hline Savannah-North & $766(17.0)$ & $781(16.4)$ & 741(11.9) \\
\hline Central Belt & $1176(41.2)$ & $1077(40.1)$ & $942(36.2)$ \\
\hline Coastal & $1162(41.8)$ & $1149(43.5)$ & $1214(51.9)$ \\
\hline \multicolumn{4}{|l|}{ Place of Residence } \\
\hline Urban & $1228(46.0)$ & $1283(47.2)$ & $1401(53.1)$ \\
\hline Rural & $1876(54.0)$ & $1724(52.8)$ & 1496(46.9) \\
\hline \multicolumn{4}{|l|}{ Occupation } \\
\hline Unemployed & $278(9.7)$ & $259(9.1)$ & $198(6.4)$ \\
\hline Specialised (Professional/Technical/Managerial) & $278(10.1)$ & $330(12.2)$ & $343(13.6)$ \\
\hline Clerical, Sales, Service & $334(12.3)$ & $526(20.6)$ & $366(15.2)$ \\
\hline Agriculture & $1538(44.3)$ & $1298(38.6)$ & $1156(32.2)$ \\
\hline Manual jobs & $629(23.6)$ & $516(19.6)$ & $823(32.5)$ \\
\hline \multicolumn{4}{|l|}{ Wealth Quintile } \\
\hline Poorest & $678(15.9)$ & $696(17.5)$ & $664(14.8)$ \\
\hline Poorer & $596(18.1)$ & $556(17.1)$ & $560(17.4)$ \\
\hline Middle & $557(19.4)$ & $489(17.1)$ & $555(20.0)$ \\
\hline Richer & $577(21.3)$ & $662(24.7)$ & $580(23.0)$ \\
\hline Richest & $696(25.3)$ & $604(23.6)$ & $538(24.9)$ \\
\hline
\end{tabular}

The total sample size $(n)=9,008(2003=3,104 ; 2008=3,007 ; 2014=2,897)$, but it varies for some variables due to missing values.

Table 2: Demographic and Sexual and reproductive health characteristics 


\begin{tabular}{|c|c|c|c|}
\hline Characteristic & $\begin{array}{l}2003 \\
\mathrm{n}(\%)\end{array}$ & $\begin{array}{l}2008 \\
\mathrm{n}(\%)\end{array}$ & $\begin{array}{l}2014 \\
\mathrm{n}(\%)\end{array}$ \\
\hline \multicolumn{4}{|l|}{ Marital status } \\
\hline Never in union & $834(28.1)$ & $937(32.3)$ & $977(35.0)$ \\
\hline Separated & $287(9.5)$ & 203(7.2) & $220(7.8)$ \\
\hline Co-habiting & $159(5.5)$ & $161(5.7)$ & $233(9.2)$ \\
\hline Married & $1824(56.9)$ & $1706(54.8)$ & $1467(48.0)$ \\
\hline \multicolumn{4}{|l|}{ Number of Wives } \\
\hline No wives & $1121(37.6)$ & $1140(39.5)$ & 1197(42.8) \\
\hline Monogynous & $1717(55.4)$ & $1662(54.7)$ & $1520(52.9)$ \\
\hline Polygynous & $266(7.0)$ & $205(5.8)$ & $180(4.3)$ \\
\hline \multicolumn{4}{|l|}{ Children Alive } \\
\hline None & $966(32.4)$ & $992(33.8)$ & $969(34.8)$ \\
\hline $1-2$ & $747(23.7)$ & $698(23.5)$ & $625(22.0)$ \\
\hline $3-4$ & 631(20.9) & $641(22.5)$ & $616(21.4)$ \\
\hline $5+$ & $760(23.1)$ & $676(20.3)$ & $687(21.9)$ \\
\hline \multicolumn{4}{|l|}{ Preferred Parity } \\
\hline At most, 1 & $24(0.9)$ & $23(0.9)$ & $33(1.3)$ \\
\hline $2-3$ & $849(29.7)$ & $880(32.2)$ & $795(31.7)$ \\
\hline $4+$ & $2149(67.4)$ & $2067(65.6)$ & $2048(66.3)$ \\
\hline Non-numeric/DK & $82(2.0)$ & $37(1.3)$ & $21(0.7)$ \\
\hline \multicolumn{4}{|l|}{ Age at First Sex (Yrs) } \\
\hline$<10$ & $5(0.2)$ & $9(0.3)$ & $15(0.5)$ \\
\hline $10-19$ & $1670(55.5)$ & $1692(57.1)$ & $1674(58.5)$ \\
\hline $20+$ & $1411(43.9)$ & $1287(42.0)$ & $1163(39.8)$ \\
\hline Inconsistent/DK & $18(0.5)$ & $19(0.6)$ & $45(1.2)$ \\
\hline \multicolumn{4}{|l|}{ Knows of a Method } \\
\hline No & $17(0.4)$ & $23(0.6)$ & $10(0.3)$ \\
\hline Yes & $3087(99.6)$ & $2984(99.4)$ & $2887(99.7)$ \\
\hline \multicolumn{4}{|l|}{ Fertility Intent } \\
\hline No more children & $766(41.4)$ & $796(46.1)$ & $767(48.1)$ \\
\hline Will have a/another child & $1107(53.0)$ & $973(49.3)$ & $830(45.7)$ \\
\hline Undecided & $102(5.6)$ & $77(4.6)$ & $96(6.2)$ \\
\hline \multicolumn{4}{|c|}{ No. of Sexual Partners (within 1 year) } \\
\hline None & $522(16.1)$ & $436(14.6)$ & $419(13.8)$ \\
\hline 1 & $2219(71.4)$ & $2140(71.4)$ & $1994(68.8)$ \\
\hline $2+$ & $359(12.5)$ & $407(14.0)$ & $484(17.4)$ \\
\hline \multicolumn{4}{|l|}{ Age of most recent partner } \\
\hline 10-19years & - & $44(2.1)$ & $32(1.7)$ \\
\hline 20-34years & - & $988(52.9)$ & $849(50.4)$ \\
\hline $35+$ years & - & $829(45.0)$ & $819(47.9)$ \\
\hline \multicolumn{4}{|c|}{ Ease of contraceptive acquisition } \\
\hline Uneasy Access & $105(4.4)$ & $126(5.0)$ & $151(5.6)$ \\
\hline Easy access & 2388(95.6) & $2457(95.0)$ & $2495(94.4)$ \\
\hline
\end{tabular}

The total sample size $(n)=9,008(2003=3,104 ; 2008=3,007 ; 2014=2,897)$, but varies for some variables due to missing values and rounding up effects. $\mathrm{DK}=$ Don't know answer, as having been returned by respondent

- Missing entries-question on age of most recent sexual partner was neither asked nor imputed for the 2003 survey.

Table 3: Inter-survey proportions test of contraceptive use by Ghanaian men: 2003-2014.

\begin{tabular}{|c|c|c|c|c|c|c|}
\hline \multirow[t]{2}{*}{ VARIABLE } & 2003 & 2008 & 2014 & 2003 vs. 2008 & 2003 vs. 2014 & 2008 vs. 2014 \\
\hline & n (\%) & n (\%) & n (\%) & Z-score(P-value) & Z-score(P-value) & Z-score(P-value) \\
\hline \multicolumn{7}{|l|}{ Contraceptive use } \\
\hline Non-Users & $1745(55.7)$ & $1975(64.2)$ & $1905(64.4)$ & $\pm 6.75(<0.0001)$ & $\pm 6.84(<0.0001)$ & $\pm 0.16(0.8730)$ \\
\hline Users & $1299(44.3)$ & $1032(35.8)$ & $992(35.6)$ & & & \\
\hline
\end{tabular}

$* * * \mathrm{p}<0.001$.

The total sample size $(n)=9,008(2003=3,104 ; 2008=3,007 ; 2014=2,897)$, but it varies for some variables due to missing values and rounding up.

e 4: Distribution of men into broad contraceptive method use, by selected socio-demographic characteristics; 2003-2014. 


\begin{tabular}{|c|c|c|c|c|c|c|c|c|c|}
\hline \multirow[b]{2}{*}{$\begin{array}{l}\text { demographic } \\
\text { cteristic }\end{array}$} & \multicolumn{3}{|l|}{2003 n (\%) } & \multicolumn{3}{|l|}{2008 n (\%) } & \multicolumn{3}{|l|}{2014 n (\%) } \\
\hline & $\begin{array}{l}\text { Modern } \\
\text { Male }\end{array}$ & $\begin{array}{l}\text { Modern } \\
\text { Female }\end{array}$ & Traditional/Other & $\begin{array}{l}\text { Modern } \\
\text { Male }\end{array}$ & $\begin{array}{l}\text { Modern } \\
\text { Female }\end{array}$ & $\begin{array}{l}\text { Traditional } \\
\text { /Other }\end{array}$ & $\begin{array}{l}\text { Modern } \\
\text { Male }\end{array}$ & $\begin{array}{l}\text { Modern } \\
\text { Female }\end{array}$ & Traditional/Other \\
\hline \multirow[t]{4}{*}{ oups } & & $(p<0.0001)$ & & & $(p<0.0001)$ & & & $(p<0.0001)$ & \\
\hline & $65(81.6)$ & $2(3.4)$ & $11(15.0)$ & $56(71.4)$ & $7(9.6)$ & $12(19.0)$ & $54(83.0)$ & $5(5.4)$ & $6(11.6)$ \\
\hline & $168(75.6)$ & $25(10.8)$ & $31(13.6)$ & 155(77.8) & $20(8.3)$ & $27(13.9)$ & $136(63.1)$ & $38(22.5)$ & $21(14.4)$ \\
\hline & $268(41.8)$ & 201(29.5) & 181(28.7) & 268(51.0) & $140(26.6)$ & $112(22.4)$ & $201(40.4)$ & $183(37.8)$ & $88(21.8)$ \\
\hline of Residence & \multicolumn{3}{|c|}{$(p=0.0006)$} & \multicolumn{3}{|c|}{$(p=0.0011)$} & \multicolumn{3}{|c|}{$(p<0.0001)$} \\
\hline & $292(49.9)$ & $157(24.8)$ & $158(24.4)$ & $305(56.4)$ & $115(21.8)$ & $114(21.8)$ & $270(48.8)$ & $154(29.0)$ & $88(22.2)$ \\
\hline & 278(39.0) & $228(33.2)$ & $186(27.8)$ & $229(45.5)$ & $160(32.0)$ & $109(22.5)$ & $169(32.8)$ & $228(52.3)$ & $67(15.0)$ \\
\hline tion Attain. & \multicolumn{3}{|c|}{$(p=0.0004)$} & \multicolumn{3}{|c|}{$(p<0.0001)$} & \multicolumn{3}{|c|}{$(p=0.0372)$} \\
\hline ucation & $49(37.7)$ & $47(34.3)$ & $39(28.0)$ & $28(33.7)$ & $32(48.1)$ & $12(18.3)$ & $17(25.1)$ & $52(63.6)$ & $7(11.4)$ \\
\hline completed. Primary & $60(39.7)$ & $44(29.3)$ & $42(30.9)$ & $59(47.3)$ & $38(33.2)$ & $25(19.6)$ & $46(40.8)$ & $69(48.6)$ & $11(10.6)$ \\
\hline secondary & $303(42.7)$ & $235(32.0)$ & 177(25.3) & $215(46.2)$ & 132(28.5) & $110(25.3)$ & $190(40.4)$ & 158(39.1) & $77(20.5)$ \\
\hline ry & $57(44.9)$ & $31(24.7)$ & $42(30.4)$ & $99(67.4)$ & $23(14.1)$ & $32(18.6)$ & $81(43.6)$ & $45(34.6)$ & $35(21.8)$ \\
\hline ation & \multicolumn{3}{|c|}{$(p<0.0001)$} & \multicolumn{3}{|c|}{$(p<0.0001)$} & \multicolumn{3}{|c|}{$(p<0.0001)$} \\
\hline ployed & $97(81.7)$ & $10(7.7)$ & $15(10.6)$ & $81(72.5)$ & $13(10.9)$ & $18(16.6)$ & $62(67.8)$ & $9(10.8)$ & $12(21.4)$ \\
\hline lised(Pros./Tech./Mgt) & $60(39.0)$ & $42(27.0)$ & $50(34.0)$ & $100(60.0)$ & $35(18.5)$ & $39(21.5)$ & $76(43.5)$ & $58(30.5)$ & $27(16.0)$ \\
\hline al, Sales, Service & $80(46.8)$ & $52(27.4)$ & $45(25.8)$ & 131(56.9) & $53(23.9)$ & $44(19.2)$ & $63(40.2)$ & $49(35.5)$ & $26(24.3)$ \\
\hline lture & $168(32.4)$ & $182(36.1)$ & 154(31.6) & $106(33.7)$ & $126(41.5)$ & $71(24.8)$ & $94(29.6)$ & $169(57.8)$ & $35(12.6)$ \\
\hline al jobs & $155(47.5)$ & $95(28.9)$ & $78(23.7)$ & 101(50.6) & $43(26.4)$ & $40(23.0)$ & $140(43.8)$ & $97(33.9)$ & $54(22.3)$ \\
\hline (of residence) & \multicolumn{3}{|c|}{$(p=0.0002)$} & \multicolumn{3}{|c|}{$(p=0.0002)$} & \multicolumn{3}{|c|}{$(p<0.0001)$} \\
\hline nah-North & $107(57.6)$ & $46(20.9)$ & $44(21.5)$ & $129(64.1)$ & $48(22.9)$ & $23(13.0)$ & $126(56.3)$ & $93(40.3)$ & $8(3.4)$ \\
\hline al Belt & $214(41.4)$ & 195(34.5) & $127(24.1)$ & $171(44.5)$ & $125(32.6)$ & $85(22.9)$ & $128(46.3)$ & $107(39.5)$ & $37(14.2)$ \\
\hline al & $249(44.7)$ & $144(25.4)$ & 173(29.9) & $234(54.4)$ & $102(22.1)$ & 115(23.5) & $185(37.3)$ & $182(39.3)$ & $110(23.4)$ \\
\hline on & \multicolumn{3}{|c|}{$(p=0.0003)$} & \multicolumn{3}{|c|}{$(p=0.1697)$} & \multicolumn{3}{|c|}{$(p=0.0061)$} \\
\hline ligion & $28(31.9)$ & $34(44.8)$ & $21(23.4)$ & $15(38.6)$ & $12(28.4)$ & $13(33.0)$ & $18(30.1)$ & $30(52.4)$ & $9(17.4)$ \\
\hline Catholic & $100(43.6)$ & $67(25.3)$ & $72(31.2)$ & 115(59.2) & $37(19.3)$ & $41(21.6)$ & $89(52.5)$ & $58(29.5)$ & $24(18.0)$ \\
\hline Christians & $318(43.2)$ & 231(30.1) & 196(26.7) & 291(49.6) & $175(28.7)$ & 133(21.8) & $226(39.0)$ & $212(39.5)$ & 108(21.6) \\
\hline
\end{tabular}

The samples in some observations sum up to $100 \pm 0.1 \%$, this is due to varying missing values and rounding up effects. The Occupational Category Specialised, consists of respondents in professional, Technical or Managerial employment.

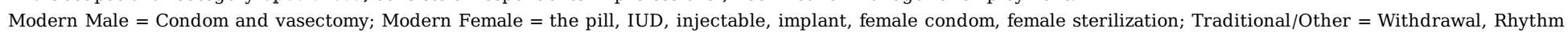
and other methods known and used only my a specific population as defined in the DHS man's questionnaire.

le 5: Distribution of men into contraceptive use consistency, by selected socio-demographic characteristics; 2003-2014. 


\begin{tabular}{|c|c|c|c|c|c|c|c|c|c|}
\hline \multirow{2}{*}{$\begin{array}{l}\text { :io-demographic } \\
\text { ıracteristic }\end{array}$} & \multicolumn{3}{|l|}{$2003 \mathrm{n}(\%)$} & \multicolumn{3}{|l|}{$2008 \mathrm{n}(\%)$} & \multicolumn{3}{|c|}{$2014 \mathrm{n}(\%)$} \\
\hline & $\begin{array}{l}\text { Never } \\
\text { used }\end{array}$ & $\begin{array}{l}\text { Inconsistent } \\
\text { Users }\end{array}$ & $\begin{array}{l}\text { Consistent } \\
\text { users }\end{array}$ & $\begin{array}{l}\text { Never } \\
\text { used }\end{array}$ & $\begin{array}{l}\text { Inconsistent } \\
\text { Users }\end{array}$ & $\begin{array}{l}\text { Consistent } \\
\text { users }\end{array}$ & $\begin{array}{l}\text { Never } \\
\text { used }\end{array}$ & $\begin{array}{l}\text { Inconsistent } \\
\text { Users }\end{array}$ & $\begin{array}{l}\text { Consistent } \\
\text { users }\end{array}$ \\
\hline groups & \multicolumn{3}{|l|}{$(p<0.0001)$} & \multicolumn{6}{|l|}{$(p<0.0001)$} \\
\hline 19 & $78(35.3)$ & $41(23.1)$ & $74(41.6)$ & $74(34.5)$ & $55(30.6)$ & $69(34.9)$ & - & - & - \\
\hline 24 & $101(19.3)$ & $124(30.4)$ & $218(50.3)$ & $109(21.4)$ & 175(35.9) & $195(42.7)$ & - & - & - \\
\hline 39 & $388(24.0)$ & $472(32.9)$ & $605(43.1)$ & $340(22.0)$ & $536(40.6)$ & $493(37.3)$ & - & - & - \\
\hline- & 313(30.8) & $329(35.4)$ & 301(33.8) & $346(31.9)$ & $403(44.6)$ & $212(23.5)$ & - & - & - \\
\hline ce of Residence & \multicolumn{3}{|c|}{$(p<0.0001)$} & \multicolumn{3}{|c|}{$(p<0.0001)$} & & & \\
\hline $\operatorname{san}$ & 218(18.3) & $417(34.8)$ & $570(46.9)$ & $227(17.1)$ & $544(43.3)$ & $512(39.7)$ & - & - & - \\
\hline $\mathrm{al}$ & $662(33.9)$ & $549(30.8)$ & $628(36.4)$ & 642(33.7) & $625(37.9)$ & $457(28.4)$ & - & - & - \\
\hline Icational Attain. & \multicolumn{3}{|c|}{$(p<0.0001)$} & \multicolumn{3}{|l|}{$(p<0.0001)$} & & & \\
\hline education & $401(58.0)$ & $169(24.4)$ & $112(17.6)$ & $364(61.5)$ & $146(26.5)$ & $61(12.0)$ & - & - & - \\
\hline ne/compl. Primary & $159(36.4)$ & 132(33.5) & 133(30.1) & $140(32.1)$ & $161(40.9)$ & $113(27.1)$ & - & - & - \\
\hline ne secondary & $270(18.8)$ & $472(33.8)$ & $658(47.4)$ & $280(20.9)$ & $566(44.7)$ & $430(34.4)$ & - & - & - \\
\hline npleted Secondary & $28(8.6)$ & $100(34.1)$ & $170(57.3)$ & $56(12.3)$ & $172(38.8)$ & $213(48.9)$ & - & - & - \\
\hline tiary & $22(8.6)$ & 93(39.7) & $125(51.7)$ & $29(8.8)$ & $124(44.2)$ & $152(47.0)$ & - & - & - \\
\hline supation & \multicolumn{3}{|c|}{$(p<0.0001)$} & \multicolumn{3}{|c|}{$(p<0.0001)$} & & & \\
\hline 3mployed & $67(22.9)$ & $91(35.3)$ & $115(41.8)$ & $74(28.8)$ & $78(29.9)$ & $107(41.3)$ & - & - & - \\
\hline cialised(Pros./Tech./Mgt) & $27(10.6)$ & 104(38.7) & $144(50.7)$ & $38(11.5)$ & $128(38.7)$ & $164(49.8)$ & - & - & - \\
\hline rical, Sales, Service & $54(14.8)$ & $109(34.6)$ & $166(50.6)$ & $86(15.9)$ & $220(44.3)$ & $220(39.8)$ & - & - & - \\
\hline iculture & $612(38.4)$ & $437(29.6)$ & $456(32.0)$ & $566(40.0)$ & $461(37.3)$ & $271(22.8)$ & - & - & - \\
\hline nual jobs & $105(17.0)$ & 208(33.3) & $303(49.8)$ & $85(16.5)$ & $254(49.6)$ & $177(33.9)$ & - & - & - \\
\hline fion (of residence) & \multicolumn{3}{|c|}{$(p<0.0001)$} & \multicolumn{3}{|c|}{$(p<0.0001)$} & & & \\
\hline rannah-North & $390(50.8)$ & $174(24.7)$ & $176(24.5)$ & $385(51.1)$ & $213(27.3)$ & $183(21.5)$ & - & - & - \\
\hline itral Belt & $273(23.4)$ & $397(34.2)$ & $486(42.4)$ & $248(22.6)$ & $475(44.1)$ & $354(33.3)$ & - & - & - \\
\hline istal & $217(19.1)$ & $395(34.3)$ & $536(46.6)$ & 236(19.3) & $481(42.0)$ & $432(38.7)$ & - & - & - \\
\hline igion & \multicolumn{3}{|l|}{$(p<0.0001)$} & \multicolumn{3}{|l|}{$(p<0.0001)$} & & & \\
\hline Religion & $79(31.7)$ & $83(35.6)$ & $74(32.7)$ & $67(35.4)$ & $69(42.6)$ & $37(22.1)$ & - & - & - \\
\hline nan Catholic & $110(21.3)$ & $146(30.6)$ & $220(48.1)$ & $117(23.4)$ & 174(36.3) & $179(40.3)$ & - & - & - \\
\hline ier Christians & $329(20.3)$ & $530(34.3)$ & $702(45.4)$ & $330(19.5)$ & $682(43.8)$ & $567(36.6)$ & - & - & - \\
\hline $\mathrm{m}$ & $255(40.7)$ & $162(29.1)$ & 172(30.3) & $215(38.8)$ & $173(34.2)$ & $151(27.0)$ & - & - & - \\
\hline d./Others & $107(51.4)$ & $45(27.3)$ & $29(21.4)$ & $140(50.5)$ & $71(31.9)$ & $34(17.6)$ & - & - & - \\
\hline
\end{tabular}

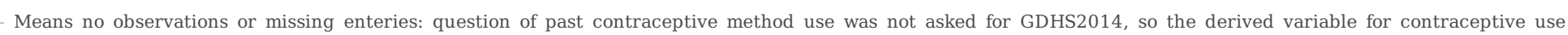
consistency could not be generated.

The samples in some observations sum up to $100 \pm 0.1 \%$, this is due to varying missing values and rounding up effects.

The Occupational Category Specialised, consists of respondents in professional, Technical or Managerial employment.

\section{Figures}

Trend in male sexual activity versus contraceptive use in Ghana, $2003-2014$

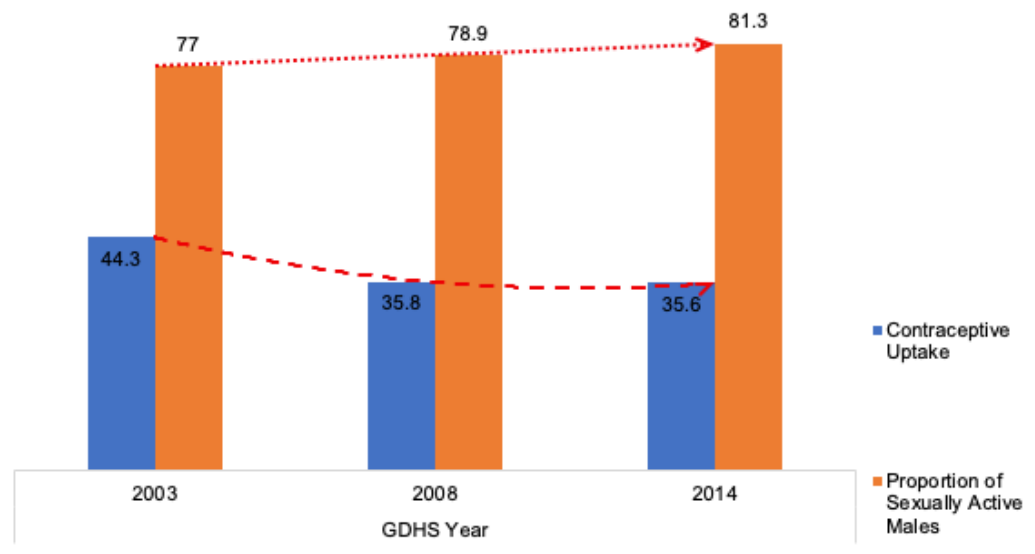

Figure 1

Trends in male sexual activity versus contraceptive use in Ghana, 2003 - 2014 


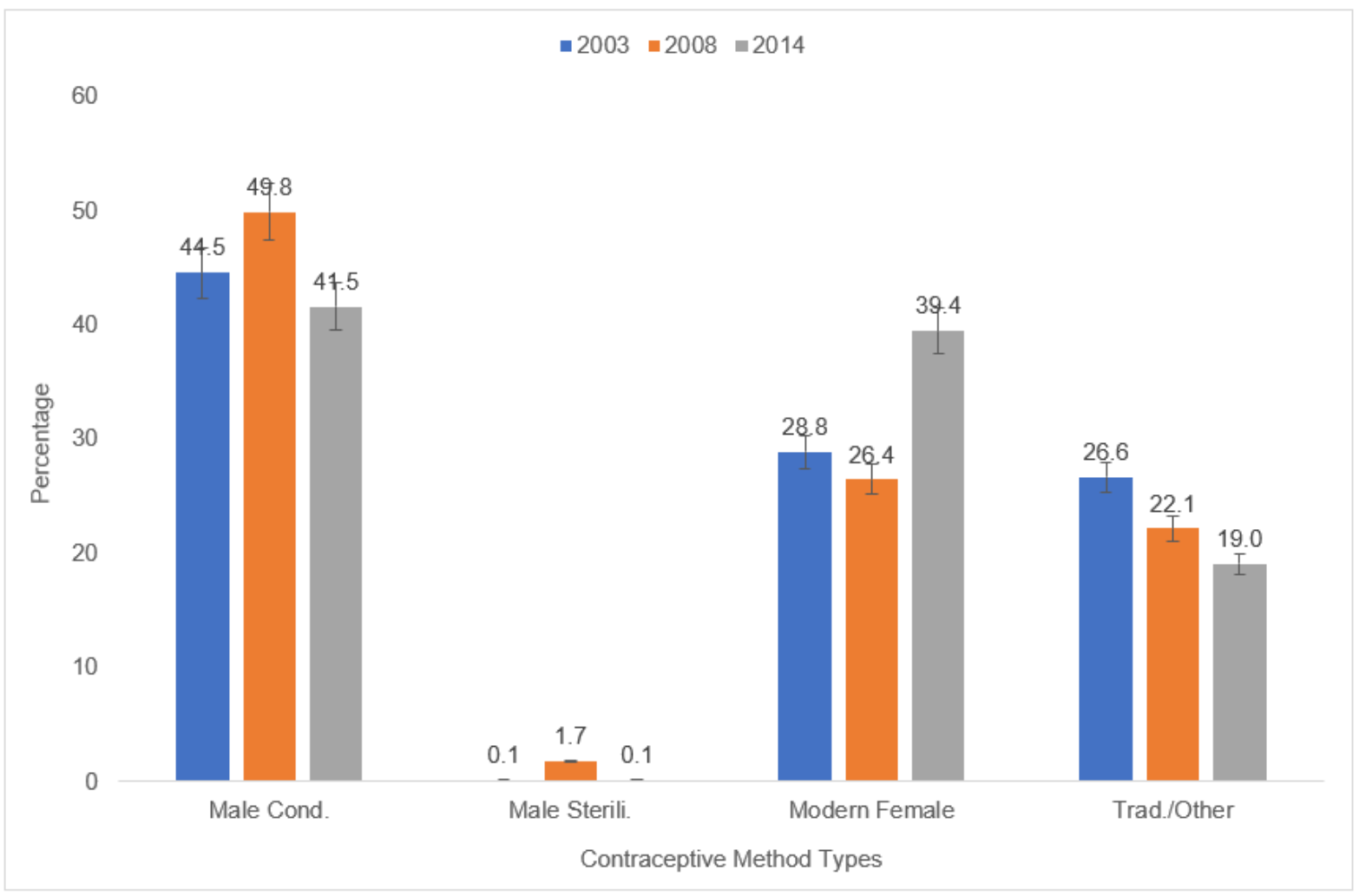

Figure 2

Pattern of male contraceptive users' method preferences in Ghana (with emphasis on modern male contraceptive method types); 2003 - 2014. 